\title{
Early motor signs of attention-deficit hyperactivity disorder: a systematic review
}

\author{
A. Athanasiadou ${ }^{1} \cdot$ J. K. Buitelaar ${ }^{2,3} \cdot$ P. Brovedani $^{4} \cdot$ O. Chorna $^{5} \cdot$ F. Fulceri $^{1} \cdot$ A. Guzzetta $^{5} \cdot$ Maria Luisa Scattoni $^{1}$
}

Received: 16 October 2018 / Accepted: 18 February 2019 / Published online: 23 February 2019

(c) The Author(s) 2019

\begin{abstract}
ADHD is a common neurodevelopmental disorder with onset of symptoms typically in early childhood. First signs of the disorder, including language delay, motor delay and temperament characteristics, may be evident as early as infancy. The present review describes published evidence about early motor signs of either children with later symptoms of ADHD or a later diagnosis of the disorder. Nine published cohort studies were included after a systematic search of related terms in PubMed and PsycInfo databases. Study eligibility criteria included: (1) report on early motor function or any motor-related signs; (2) the presence of a participants' assessment by/at 12 months of age; (3) report of a later presence of ADHD symptoms. The limited number of reports included suggests an association between mild early neurological markers and later developmental coordination disorder and motor overflow movements. Unfortunately, due to their small sample sizes and focus on group reports rather than individuals, they have limited power to find strong associations. Early motor indicators of ADHD, if present, appear to be non-specific, and therefore not yet useful in clinical screening. Spontaneous motility seems to be a promising measure for early ADHD detection, although further studies with large cohorts are recommended to determine its clinical role in children at risk for ADHD.
\end{abstract}

Keywords Attention-deficit hyperactivity disorder (ADHD) · Early motor signs · Infancy · General movements (GMs)

\section{Introduction}

ADHD is a common neurodevelopmental disorder with symptoms typically emerging during early school years and a worldwide prevalence estimated between 5 and $7 \%[1,2]$.

A. Guzzetta and Maria Luisa Scattoni: equally contributing authors.

Maria Luisa Scattoni

marialuisa.scattoni@iss.it

1 Research Coordination and Support Service, Istituto Superiore di Sanità, Viale Regina Elena 299, 00161 Rome, Italy

2 Department of Cognitive Neuroscience, Radboud University Medical Centre, Nijmegen, The Netherlands

3 Karakter Child and Adolescent Psychiatry, Nijmegen, The Netherlands

4 IRCCS Stella Maris, Scientific Institute of Child Neurology and Psychiatry, Calambrone, Pisa, Italy

5 Department of Developmental Neuroscience, IRCCS Stella Maris, Calambrone, Pisa, Italy
ADHD is characterized by a persistent pattern of inattention and/or hyperactivity-impulsivity which hinders adaptive functioning or compromises development [3]. To be diagnosed with ADHD, symptoms of the disorder must be observed in two or more settings and have negative effects on fundamental aspects of the child's daily activities. Cooccurring psychiatric conditions are frequently observed, including oppositional defiant disorder (ODD), conduct disorder, anxiety disorders, depression, autism spectrum disorder (ASD) and learning disabilities [4-9]. Children with ADHD also often face difficulties in everyday life, including in their social relationships, academic performance and achievements, and low self-esteem [10]. In addition, they may experience deficits in visuospatial and verbal working memory, vigilance, inhibitory control and planning, problems with coordination of gross and fine motor functions, sequencing of movements [11], difficulties with working memory and self-regulation of emotions, language and speech deficits, arousal and activation and temporal information processing and timing [11-17].

Investigating early motor signs during the first year of life could be of high importance for the study of early 
biomarkers of common neurodevelopmental disorders, such as ADHD and ASD, which may share neurobiological underpinnings [18-21]. There is evidence that children with ADHD have worse gross motor and fine motor skills than their typically developing peers [22]. Two hypotheses on the source of the motor disadvantages in individuals with ADHD have been put forward. The first hypothesis attributes these motor abnormalities to the core triad of ADHD symptoms: hyperactivity, impulsivity and inattention. According to this theory, inattention [22] and vigilance problems [23] affect motor skill development. The second hypothesis attributes the motor delays to a likely presence of a comorbid disorder such as developmental coordination disorder (DCD) or ASD [23, 24]. Overall, research indicates that attention and impulse control are strongly predictive of gross and fine motor skill development in children with ADHD [24].

The neurobiological basis for the primary theory is that delays in brain maturation are associated with delays in motor development and specific motor skills [25] in the ADHD population. More specifically, motor control and executive function rely on the integrity of the thalamus, known to be affected in individuals with ADHD [26]. In addition, cortical thickness structure abnormalities and hypoactivation in the right globus pallidus, the right frontal cerebellum and frontal region, reported to be present in $\mathrm{ADHD}$, are responsible, among other functions, for precise motor control.

The second theory-of the comorbidity between ADHD and DCD as the potential cause of motor delays-is also supported by neurological findings. Although the comorbidity of ADHD and DCD is not often taken into account, a high percentage of children with ADHD (30-50\%) experiences co-occurring DCD with a familial correlation of 0.38 [27-31]. Almost half of individuals with ADHD (34\% out of $63 \%$ ) have been reported to show motor difficulties within the DCD range, particularly in manual dexterity. These difficulties result in low self-esteem and reduced popularity in children $[29,30]$. At present, there is evidence that a dopamine-induced imbalance of basal ganglia neuro circuits could also be involved in the underlying neurobiological mechanisms [32, 33]. Thus, health care professionals should be aware of the high prevalence of this co-occurring motor condition.

Cerebellar abnormalities in children with DCD could also explain postural control and balance problems. Children with ADHD without co-occurring DCD have shown fine motor fluency and flexibility, but when a co-occurring DCD condition is present, fine motor difficulties are observed [34]. However, few studies have focused on brain region atypicalities in ADHD children with co-occurring DCD. McLeod et al [35]. found that these children have increased functional connectivity between the primary motor cortex and brain regions involved in motor control, and claimed this is fundamental for their ability to organize and successfully execute movement [36]. However, motor abnormalities in ADHD cannot be attributed only to the co-occurence with DCD, since children with ADHD without DCD do also have motor difficulties, although these are less prominent [37].

Since ADHD symptoms usually emerge during the early school years, both clinical and neurobiological research have focused on school-aged children, adolescents and adults. Interest in early signs of ADHD is, however, rapidly growing. Recent studies report initial evidence of some indicators appearing prior to school-age, including difficult temperament, and language and motor delay [38, 39]. Still, a little is known about whether early signs of ADHD can be reliably observed during the first year of life. This may be partly due to the relative immaturity of cognitive functions related to sustained attention and focused activity during the first months of life, and to the consequent difficulty in reliably assessing them. Increasing evidence suggests that specific motor behaviors observed during the first months of life may be a marker of neurodevelopmental disorders, which show clinical and genetic overlap with ADHD [40]. Some authors suggest that increased activity in infancy could be considered an early sign of ADHD [38, 41-45]. However, other researchers argue that the quality of movements in infancy per se does not predict the disorder [46-48].

To shed light on early motor signs in ADHD and their emergence, we systematically reviewed the publications investigating motor behavior during the first year of life in infants who later develop subclinical ADHD symptoms or are diagnosed with the disorder.

\section{Methods}

A systematic literature search was performed in PubMed and PsycInfo databases including the following keywords: (1) "ADHD" OR "Attention deficit hyperactivity disorder" OR "Attention deficit-hyperactivity disorder"; (2) AND "infant*" OR "infancy" OR "neonatal" OR "newborn" OR "baby"; AND "movement*" OR "motor" OR "sensorymotor" OR "sensori-motor" OR "motion". A systematic review of the references of the included papers was also performed to ensure a thorough search. The first search was performed in July 2016, and once more in January 2017, which yielded one additional relevant article.

Study eligibility criteria included: (1) report on early motor function or any motor-related signs; (2) the presence of a participants' assessment by/at 12 months of age; (3) report of a later presence of ADHD symptoms. The first selection was based on the study titles, as identified by one of the authors (AA). Second, abstracts were independently screened for eligibility by two authors (AA and OC). Two authors (AA and OC) independently performed the data 
extraction and discussed their findings to reach a consensus. Full texts of potentially relevant papers were read to ascertain whether the study met all selection criteria.

The following data were extracted from the included articles: type of study (e.g., longitudinal, cross-sectional, or case control, both retrospective and prospective), source population (e.g., population-based or hospital referrals), participants' age range, type and timing of early motor signs, type and timing of ADHD diagnosis (based on the DSM-5) [3], or ADHD-specific symptoms (based on interviews/questionnaires), and the study outcome assessment.

Quality ratings were conducted using a modified Methodological Quality Checklist [49] developed for assessing the methodological quality of both randomized and nonrandomized studies. Two of the authors (AA and OC) performed the quality ratings independently, and when necessary, reached a decision by consensus. Thirteen out of the 27 items of the scale were used in the present study, after removing those that applied only to randomized trials and intervention studies. This modified scale yielded a final rating from 0 to 14 points (see Table 1 ). The same approach was previously used in a systematic review on ADHD [50].

\section{Results}

In total, 417 articles were identified via the database search on both PubMed and PsycInfo; 30 studies were selected for review. Nine articles were included after completing the selection process (see flow diagram in Fig. 1). All included publications were cohort studies. The findings of all reviewed articles are reported in Table 2. Design and outcome measures differed substantially among the studies, which made a formal meta-analysis not feasible. The quality ratings of the included studies ranged between 11 and 14 out of 14 (see Table 1). Overall, the reports were of good quality.

\section{Spontaneous movements during the first 3 months of age}

Three prospective studies [42-44] explored very early motor signs of ADHD. They focused on the quality of spontaneous motility, as assessed by the General Movements (GMs) approach with infants at risk for neurodevelopmental delays. General movements are distinct spontaneous movement patterns that infants exhibit without external stimulation [53]. Investigations of early motor indicators of ADHD through the evaluation of GMs have included both healthy infants and those with increased risk for neurodevelopmental delays. Consistent with the GM method, the investigators evaluated infants several times in the first months of life and then followed up with standardized behavioral assessments at school-age. One study [42] reported that infants with definitely abnormal GMs including extremely reduced complexity, variability and fluency were at significantly increased risk to develop cerebral palsy. Furthermore, a significant association was found between milder GM abnormalities and attention problems at 4-9-year follow-up (odds ratio $6.88,95 \%$ CI 1.39-33.97) assessed by the DSM-IV ADHD questionnaire. In particular, unlike infants with normal fidgety movements at 3-4 months, children with mildly abnormal GMs were significantly more distractible, inattentive and hyperactive as assessed by the Groningen Perinatal Project Questionnaire (GPPQ) and the DSM-IV ADHD Questionnaire for Attention-Deficit/Hyperactivity Disorder. Another study [40] indicated that abnormal GMs at both writhing and fidgety age were significantly associated with the presence of ADHD only when it was co-occurrent with another psychiatric diagnosis, but not when it was present in isolation. Furthermore, abnormal GMs at fidgety age were related to a higher total score on the DSM-IV ADHD questionnaire, and in particular, to higher subscores for hyperactivity and impulsivity, and lower subscores for inattention. Another report of GMs with preterm born infants, however, showed no significant association between GMs and attention problems at 7-11 years, as assessed by a separate subscale of the Child Behavior Checklist (CBCL) [55]. This dissociation was even stronger when children with cerebral palsy were excluded from the analysis [44].

\section{Motor signs during the first year}

Of the included reports, four were large longitudinal cohort studies exploring early neurodevelopment in the general population $[38,46,48]$ or in families with lower socioeconomic status [45]. Neurodevelopmental characteristics of children with ADHD symptoms or an ADHD diagnosis were compared to the same characteristics of control children.

A retrospective chart review study of 58 children diagnosed with ADHD at school-age and 58 controls that participated in a population-based developmental program at a 'Well-Baby' clinic evaluated longitudinal data from birth, 1-, 3-, 9- and 18-month visits [38]. Higher incidence of emergency caesarian sections, smaller head circumference at 3 months and feeding or sleeping difficulties before 6 months were all identified as early signs significantly correlated with ADHD. However, the only motor-related early sign identified was a delay in gross motor development, as assessed by the Denver Developmental Screening Test (DDST) [54]. A delay in gross motor movements was identified at 9 months of age in $34.5 \%$ of the ADHD group compared to $13.8 \%$ of the controls. The most reported deviation from typical gross motor development was the refusal to maintain supine position, which led to difficulties in head control, and thus, to general motor development difficulties. The delay was reported to be relatively mild, and attributed 


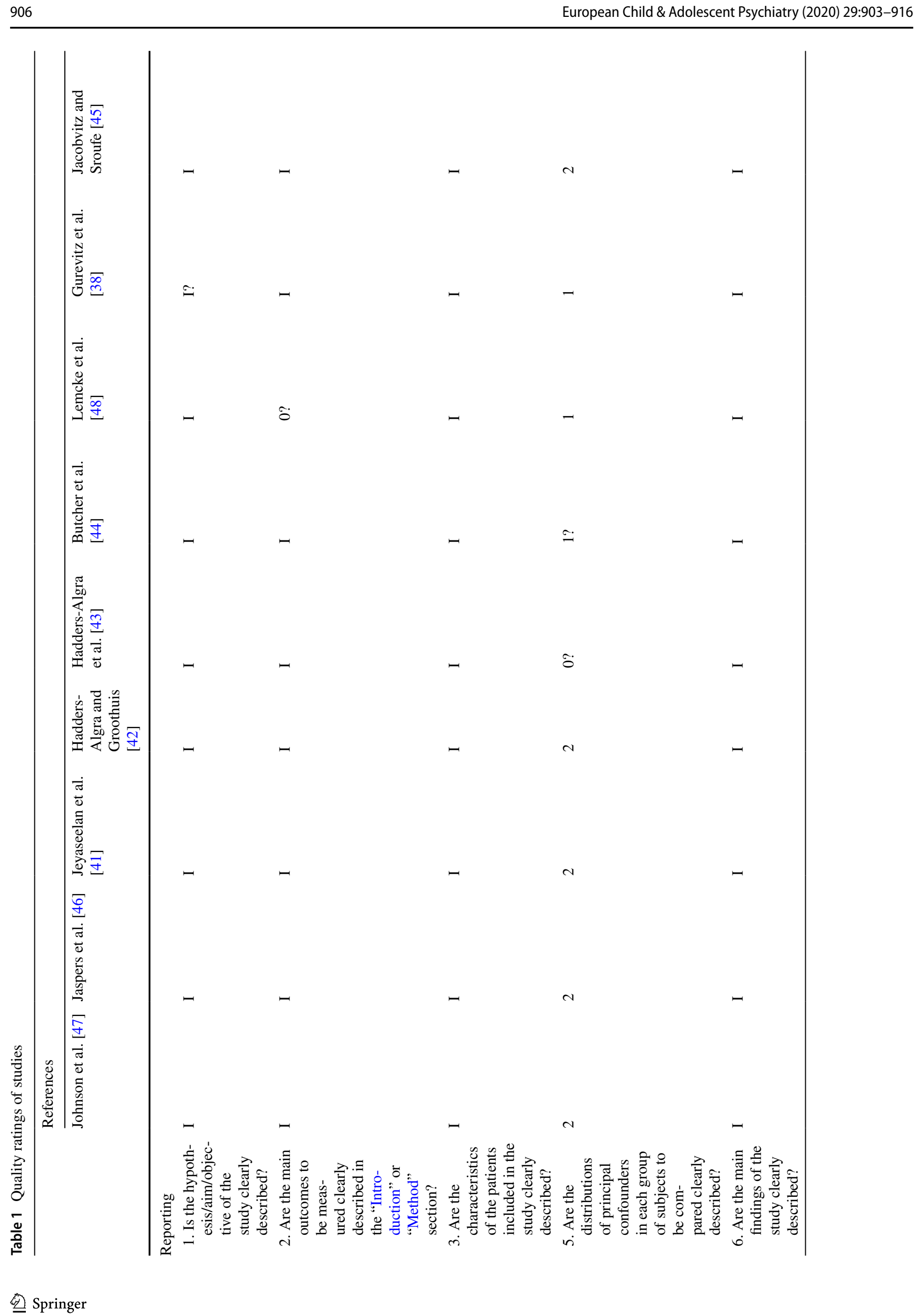




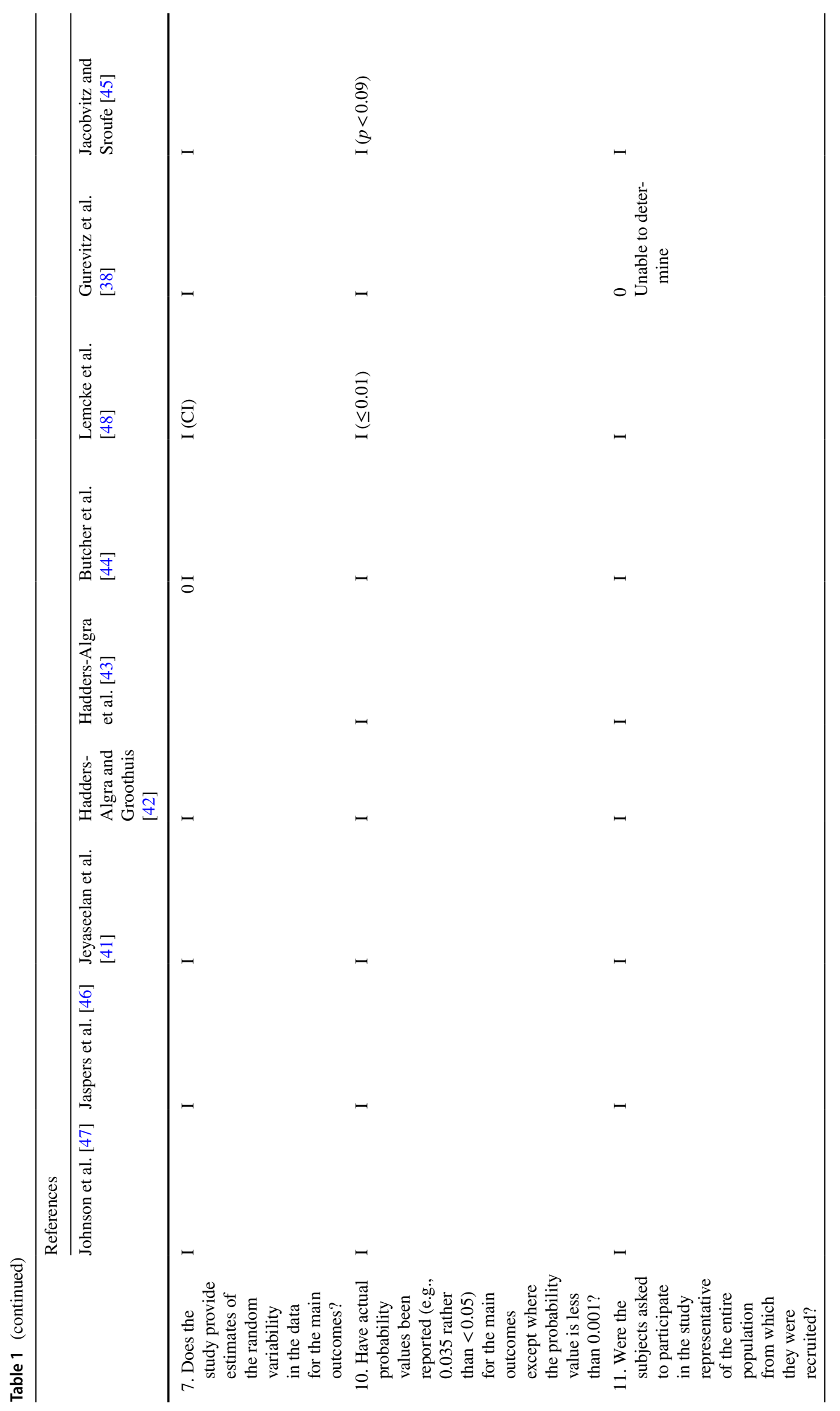




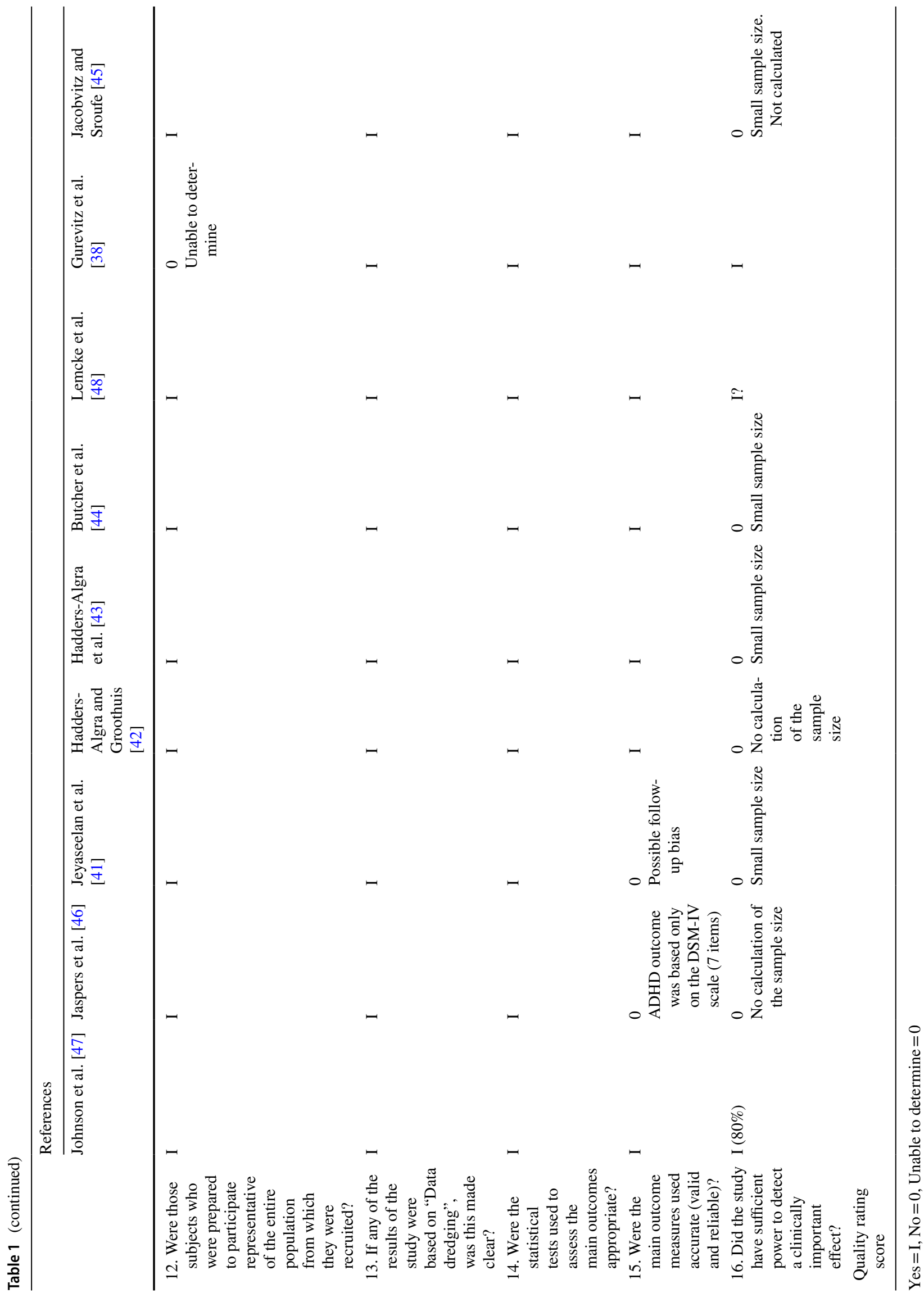


Articles identified via database

searching, First search.

$\mathrm{N}=270$ (PubMed) +147 (Psyclnfo)

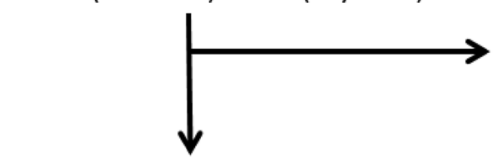

Articles selected for abstract/full

review

$\mathrm{N}=18$ (PubMed) +12 (Psyclnfo)

\begin{tabular}{|c|}
\hline $\begin{array}{l}\text { Manual Inspec } \\
\text { reference lists } \\
n=3\end{array}$ \\
\hline $\begin{array}{l}\text { Second search } \\
n=1\end{array}$ \\
\hline
\end{tabular}

\author{
Articles excluded based on title/abstract \\ review \\ n=258 (PubMed), 129 (Psyclnfo)
}

Articles excluded based on abstract/full review

$\mathrm{N}=25$

Reasons for exclusion:

- Not relevant for the research $(n=19)$

- Not fullfilling the inclusion criteria $(n=4)$

- Not published in English ( $n=2)$

Fig. 1 Selection process

to physical characteristics including lax ligaments and hypotonia. Importantly, some children in the ADHD group were early achievers and some were late achievers, with both subgroups reported by the authors as showing "extreme" motor behavior.

A prospective study exploring early development in 267 infants from families with lower socioeconomic status [45] also included a smaller retrospective evaluation of 34 hyperactive children and 34 age-matched controls. The presence of hyperactivity was determined at around 6 years of age from subscores of the teacher-administered CBCL [55]. Thirty-eight child behavior variables were obtained during the first 2.5 years of life including neonatal behavioral assessments, mother-administered Carey questionnaire evaluating temperament, activity and attention, and other ratings of activity at 3 and 6 months of age [56]. Children who were hyperactive in kindergarten had been motorically less mature at 7 days old as assessed by the motor maturity Brazelton factor [57]. However, this was the only variable, out of the 38, which differentiated hyperactive children from typical children.

Another large study by Lemcke et al. [48] included 2034 children with a diagnosis of ADHD, who came from a large population-based cohort from the Danish National Birth Cohort (DNBC). As part of the DNBC, 76,286 mothers were interviewed about their child's development at 6 and 18 months. Children were followed up between 8 and 14 years of age, when they were assessed for the presence of ADHD based on International Classification of Diseases, 10th Revision (ICD-10) criteria. The interview at 6 months of age explored specific aspects of motor development, such as the infant holding their head straight while being picked up, sitting up while on an adult's lap, rolling over from back to stomach, crawling on the stomach. When comparing the ADHD group with the total study cohort, the only significant finding in the ADHD group was a higher number of infants who could not sit up straight when put on lap at 6 months $(p \leq 0.001)$.

Similarly, Jaspers et al. [46] studied early indicators of ADHD (and ASD) in a population of 1816 subjects who took part in a prospective cohort study among (pre-)adolescents in the general population. Early indicators were obtained by identifying correlations between routine data from the community pediatric services during the first year of life and ADHD-risk as measured by parent-administered CBCL between 11 and 17 years old. Early motor indicators 


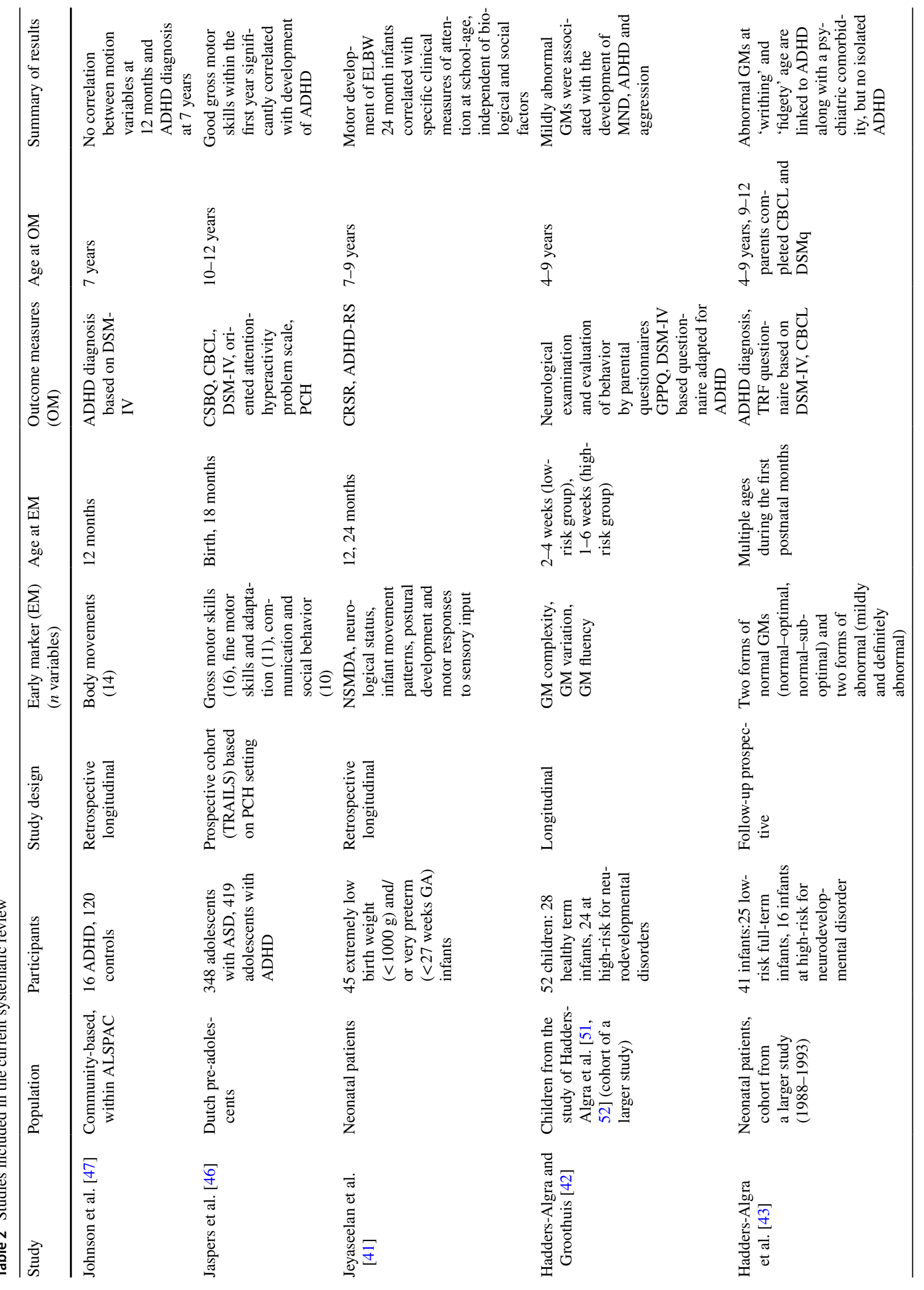




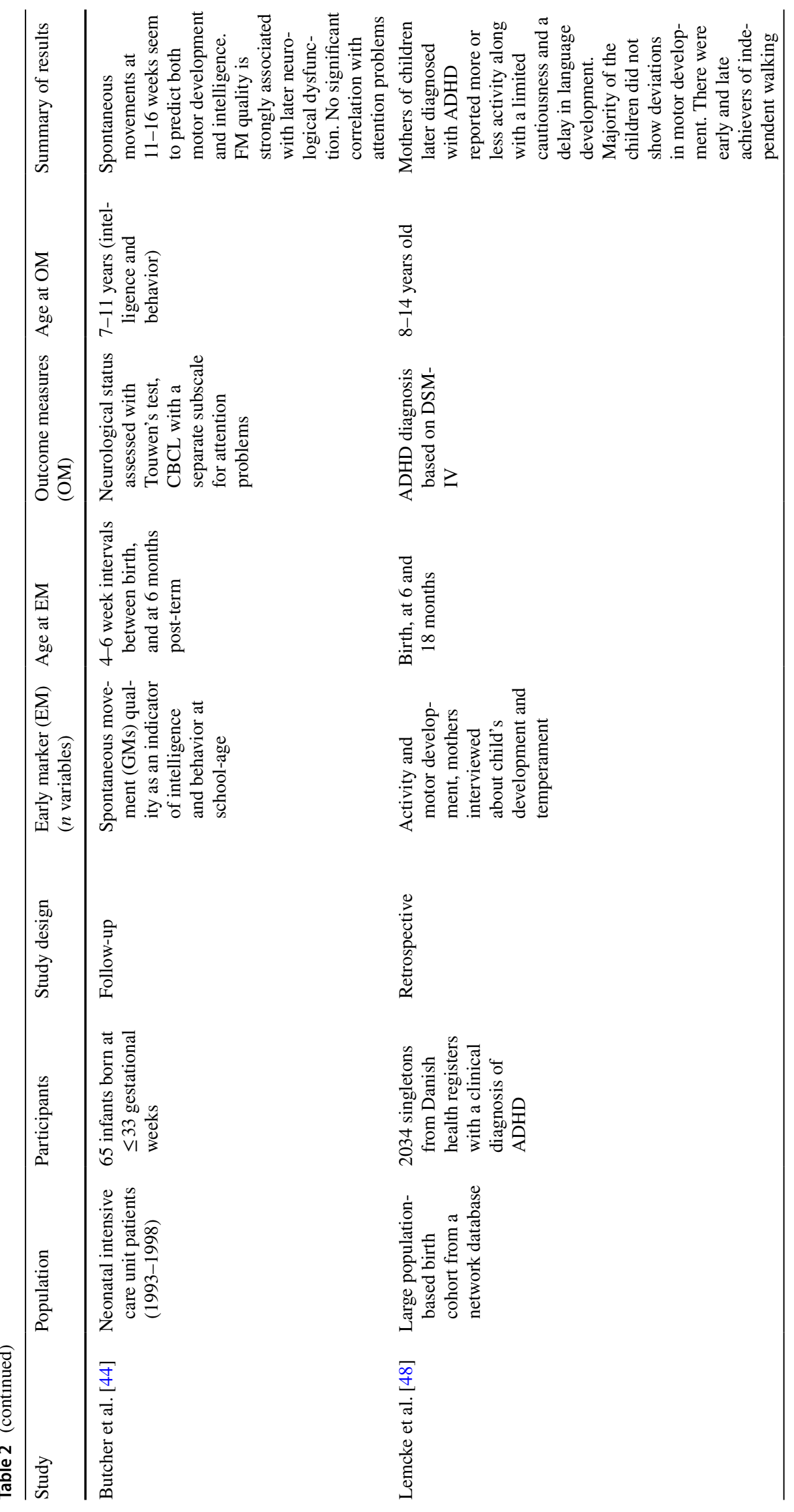




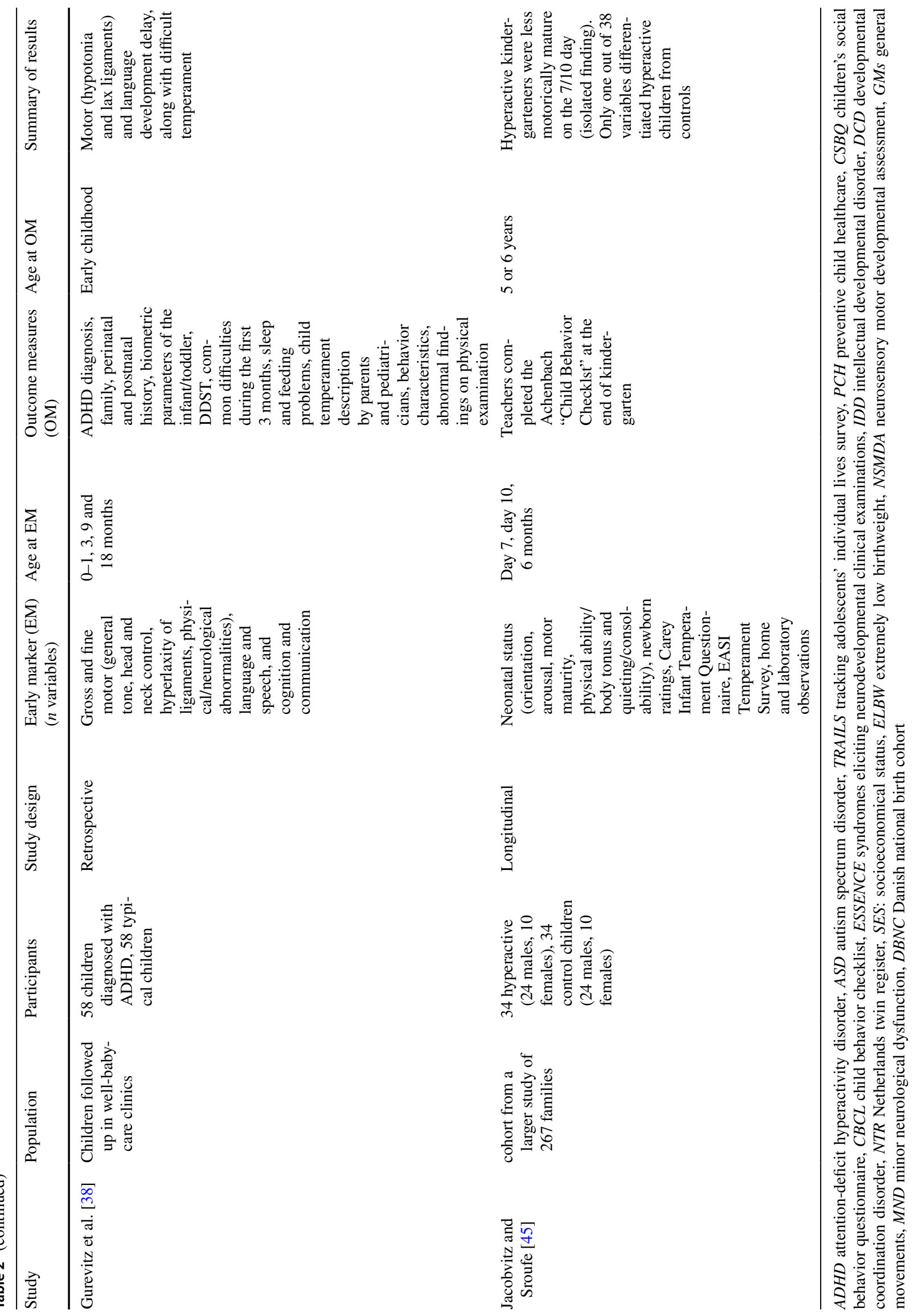


as assessed by the Van Wiechen scheme [58] explored the scores of gross and fine motor skills and social behavior. This study reports that good gross motor skills within the first year were significantly correlated with the development of ADHD problems.

\section{Motor signs at 1 year}

Two studies explored motor signs at 12 months of age. Johnson et al. [46] studied 16 children with ADHD (based on DSM-IV criteria), and 120 control children. Both groups were extracted from a focus study group within a larger community-based cohort, the Avon Longitudinal Study of Parents and Children (ALSPAC). As part of the ALSPAC focus study group, 1240 infants at 1 year took part in a video-recorded parent-infant interaction in a naturalistic environment [59]. Software was used to track 8 body markers $[(\operatorname{nose}(\mathrm{N})$, right $(\mathrm{RH})$ and left hand $(\mathrm{LH})$, right $(\mathrm{RE})$ and left elbow (LE), right (RS) and left shoulder (LS) and pelvis $(\mathrm{P})]$. Thirteen motion summaries were used to determine robust indexes of motor activity including speed, acceleration along with their variability, acceleration, periodicity and agitation. Finally, 14 out of 104 variables were chosen for further investigation, including the speed and variability of 5 markers (N, RH, LH, LE, LS), the agitation of $3(\mathrm{~N}$, LH, LE) and rhythmic movement of one marker (RH). No significant association was found between the motion variables examined and the diagnosis of ADHD at 7 years. A correlation between motor activity and scores on the inattentiveness subscale of the ADHD diagnostic interview was found in male participants, but considered questionable by the authors due to the small size of the subsample $(n=14)$.

Lastly, motor signs of extremely low birth weight and very preterm infants were evaluated at 12 months with the Neurosensory Motor Developmental Assessment (NSMDA) and these scores were examined together with clinical and psychometric measures of attention at 7-9 years of age [41]. At 12 months, NSMDA evaluated gross and fine motor function, motor patterns, neurological status, postural development, and the reaction to sensory input. Measures of attention in childhood included the Conner's Rating Scale Revised-Long Form (CRSR) and Du Paul ADHD Rating Scale IV (ADHD-RS).

\section{Discussion}

ADHD is a neurodevelopmental disorder characterized by a pattern of inattention and/or impulsivity and hyperactivity across different contexts. Since early identification of ADHD is essential to optimize the quality of life, there is growing research interest in the investigation of early clinical and behavioral features of children later diagnosed with ADHD.
To further investigate this topic, we reviewed the literature summarizing the full spectrum of motor impairments which might be potential early indicators of ADHD. In particular, we included studies which report motor skills of infants during the first year of life who subsequently (1) received a formal psychiatric diagnosis of ADHD based on DSM-IV or the ICD-10, or (2) whose behaviors were related to high levels of ADHD symptoms, as identified by questionnaires.

\section{Diagnosis of ADHD and early motor signs}

Four of nine studies presented included a formal diagnosis of ADHD through a psychiatric assessment [36, 42, 47, 48]. The clinical diagnosis of ADHD was either based on the criteria of the DSM-IV or the ICD-10. In these studies, children with ADHD showed atypical motor development detectable in the first 9 months [47], but not as late as 12 months, when compared to typically developing infants.

The first detectable abnormalities of motor development, GMs, in children later diagnosed with ADHD seem to be associated more strongly with ADHD when it is cooccurring with other psychiatric disorders than with ADHD alone. This is consistent with previous reports suggesting that ADHD with a co-occurring disorder is a probably more severe form of ADHD [60, 61]. Indeed, although children diagnosed with cerebral palsy were excluded from HaddersAlgra's [42] study, to avoid bias related to the known association between cerebral palsy and behavioral problems, their study population was at high risk for neurodevelopmental problems [43]. Therefore, the relationship found in this study between abnormal GMs and ADHD still suggests that the vulnerability of periventricular white matter, typical of preterm subjects and associated to abnormal GMs, may contribute to the development of ADHD with co-occurring conditions [62, 63]. In any case, the results of Hadders-Algra [42] should be considered as preliminary, since its sample size was insufficient to reach definite conclusions [43].

During the time of spontaneous motility ( $0-5$ months) and beyond, at least up to 9 months, a delay in gross motor function was significantly more common in infants who later developed ADHD. At 3 and 9 months, Gurevitz et al. [38] reported a delay in gross motor development as assessed by the Denver Developmental Screening Test, while at 6 months Lemcke et al. [48] found a significantly higher number of infants who could not sit up straight when put on lap in the ADHD group. Motor delay seems to be no longer present at 12 months, according to the findings by Johnson et al. [46], who found no significant association between a series of motor variables at 12 months with the clinical diagnosis of ADHD at 7 years of age. As the authors hypothesized, their inconclusive outcome could be due to the small sample size of the study. 
Auerbach et al. [64], examining 7-month-old infants at risk of ADHD based on mother reports and observational measures, found that children with later ADHD were significantly different from the control group in respect of behavioral states, interest and activity level.

Overall, these results support the hypothesis of a link between mild neurological markers and developmental coordination disorder, and motor overflow movements, all of which are more common in children with ADHD [64]. Nevertheless, non-specific factors related to physical characteristics, such as lax ligaments and hypotonia, are also likely to have contributed to the described gross motor delay.

\section{Symptoms of ADHD and early motor signs}

Results are more inconsistent when it comes to the relationship between early motor signs and later subclinical ADHD symptoms. Some reports state that early spontaneous motility is correlated with attention problems, including less motoric maturity at 7 days of life in children who are later hyperactive in kindergarten. Similarly, Jeyaseelan et al. [41] found a correlation between decreased motor and sensory assessment scale scores (NSMDA) and psychometric measures of verbal attention span at 12 months. However, Jaspers et al. [46] found that ADHD problems were significantly correlated with good gross motor skills, as defined by the authors, within the first year of life.

There are multiple possible reasons for these inconsistent findings. The populations that were studied are extremely heterogeneous and have different degrees of risk for ADHD, from infants with clinical signs of early hyperactivity to those who are born preterm or were small for gestational age. The assessments used to test the presence and characteristics of early motor signs were also heterogeneous, including parental questionnaires, qualitative and quantitative assessments of motor behavior, and early attentional measures. Finally, the diagnostic instruments that were used to evaluate later presence of ADHD symptoms differed among studies, making comparisons very challenging.

The limitation of our review is that the studies which are included have small sample sizes and focus on group reports rather than individuals, so they have limited power to find strong associations. Although the studies are of high quality according to the rating scheme, the outcome measures have questionable accuracy (see Table 1).

\section{Concluding remarks}

In summary, there are a limited number of reports investigating gross motor function in the first year of life in children who later have ADHD symptoms or are diagnosed with ADHD. Early detection of ADHD-related motor abnormalities would be important to provide a timely diagnosis, and most importantly, early intervention, especially in case of a very strong association between ADHD and early motor signs. This would assist clinicians in the continuous development and implementation of interventions at a very critical period of child development, when the brain is rapidly developing and neuroplasticity is highest. Unfortunately, data emerging from this review show that early motor signs, if present, seem to be non-specific, and therefore not yet worth implementing in clinical screening protocols. Some qualities of spontaneous motility seem promising as an early detection tool for risk of ADHD, although further studies based on the individual, with larger cohorts and more specific and semi-quantitative scoring systems, are necessary to determine their clinical role in populations at risk for ADHD.

Funding Horizon 2020 programme of the European Union (Marie Skłodowska-Curie grant BRAINVIEW-642996).

Conflict of interest None.

Open Access This article is distributed under the terms of the Creative Commons Attribution 4.0 International License (http://creativeco mmons.org/licenses/by/4.0/), which permits unrestricted use, distribution, and reproduction in any medium, provided you give appropriate credit to the original author(s) and the source, provide a link to the Creative Commons license, and indicate if changes were made.

\section{References}

1. Polanczyk G, Rohde LA (2007) Epidemiology of attention-deficit/ hyperactivity disorder across the lifespan. Curr Opin Psychiatry 20(4):386-392. https://doi.org/10.1097/YCO.0b013e3281568d7a

2. Willcutt EG (2012) The prevalence of DSM-IV attention-deficit/ hyperactivity disorder: a meta-analytic review. Neurother J Am Soc Exp NeuroTher 9(3):490-499. https://doi.org/10.1007/s1331 1-012-0135-8

3. American Psychiatric Association (2013) Diagnostic and statistical manual of mental disorders, 5th edition (DSM-5). American Psychiatric Association, Philadelphia. https://doi.org/10.1176/ appi.books.9780890425596

4. Alzaben FN, Sehlo MG, Alghamdi WA, Tayeb HO, Khalifa DA, Mira AT et al (2018) Prevalence of attention deficit hyperactivity disorder and comorbid psychiatric and behavioral problems among primary school students in western Saudi Arabia. Saudi Med J 39(1):52-58. https://doi.org/10.15537/smj.2018.1.21288

5. Gordon-Lipkin E, Marvin AR, Law JK, Lipkin PH (2018) Anxiety and mood disorder in children with autism spectrum disorder and ADHD. Pediatrics. https://doi.org/10.1542/peds.2017-1377

6. Quintero J, Morales I, Vera R, Zuluaga P, Fernández A (2017) The impact of adult ADHD in the quality of life profile. J Atten Disord 1:1. https://doi.org/10.1177/1087054717733046

7. Reimherr FW, Marchant BK, Gift TE, Steans TA (2017) ADHD and anxiety: clinical significance and treatment implications. Curr Psychiatry Rep 19(12):109. https://doi.org/10.1007/s1192 0-017-0859-6

8. Rimal H, Pokharel A (2016) Prevalence of attention deficit hyperactivity disorder among school children and associated co-morbidities - a hospital based descriptive study. Kathmandu Univ Med J (KUMJ) 14(55):226-230 
9. Willcutt EG, Pennington BF, Smith SD, Cardon LR, Gayán J, Knopik VS et al (2002) Quantitative trait locus for reading disability on chromosome $6 \mathrm{p}$ is pleiotropic for attention-deficit/ hyperactivity disorder. Am J Med Genet 114(3):260-268

10. Faraone SV, Biederman J, Spencer T, Mick E, Murray K, Petty $\mathrm{C}$ et al (2006) Diagnosing adult attention deficit hyperactivity disorder: are late onset and subthreshold diagnoses valid? Am J Psychiatry 163(10):1720-1729. https://doi.org/10.1176/ ajp.2006.163.10.1720 (quiz 1859)

11. Barkley RA (1997) Attention-deficit/hyperactivity disorder, selfregulation, and time: toward a more comprehensive theory. J Dev Behav Pediatr JDBP 18(4):271-279

12. Wehmeier PM, Schacht A, Dittmann RW, Banaschewski T (2010) Minor differences in ADHD-related difficulties between boys and girls treated with atomoxetine for attention-deficit/hyperactivity disorder. Atten Deficit Hyperact Disord 2(2):73-85. https://doi. org/10.1007/s12402-010-0022-2

13. Berlin L, Bohlin G, Nyberg L, Janols L-O (2004) How well do measures of inhibition and other executive functions discriminate between children with ADHD and controls? Child Neuropsychol J Norm Abnorm Dev Child Adolesc 10(1):1-13. https://doi. org/10.1076/chin.10.1.1.26243

14. Schroeder VM, Kelley ML (2009) Associations between family environment, parenting practices, and executive functioning of children with and without ADHD. J Child Fam Stud 18(2):227235. https://doi.org/10.1007/s10826-008-9223-0

15. Ponitz CC, McClelland MM, Matthews JS, Morrison FJ (2009) A structured observation of behavioral self-regulation and its contribution to kindergarten outcomes. Dev Psychol 45(3):605-619. https://doi.org/10.1037/a0015365

16. Faraone SV, Asherson P, Banaschewski T, Biederman J, Buitelaar JK, Ramos-Quiroga JA et al (2015) Attention-deficit/hyperactivity disorder. Nat Rev Dis Primers 1:15020. https://doi.org/10.1038/ nrdp. 2015.20

17. Tillman C, Brocki KC, Sørensen L, Lundervold AJ (2015) A longitudinal examination of the developmental executive function hierarchy in children with externalizing behavior problems. $\mathrm{J}$ Atten Disord 19(6):496-506. https://doi.org/10.1177/1087054713 488439

18. Rommelse NNJ, Franke B, Geurts HM, Hartman CA, Buitelaar JK (2010) Shared heritability of attention-deficit/hyperactivity disorder and autism spectrum disorder. Eur Child Adolesc Psychiatry 19(3):281-295. https://doi.org/10.1007/s00787-010-0092-x

19. Rommelse NNJ, Peters CTR, Oosterling IJ, Visser JC, Bons D, van Steijn DJ et al (2011) A pilot study of abnormal growth in autism spectrum disorders and other childhood psychiatric disorders. J Autism Dev Disord 41(1):44-54. https://doi.org/10.1007/ s10803-010-1026-7

20. Rommelse N, Antshel K, Smeets S, Greven C, Hoogeveen L, Faraone SV, Hartman CA (2017) High intelligence and the risk of ADHD and other psychopathology. Br J Psychiatry J Ment Sci 211(6):359-364. https://doi.org/10.1192/bjp.bp.116.184382

21. Visser JC, Rommelse NNJ, Greven CU, Buitelaar JK (2016) Autism spectrum disorder and attention-deficit/hyperactivity disorder in early childhood: a review of unique and shared characteristics and developmental antecedents. Neurosci Biobehav Rev 65:229-263. https://doi.org/10.1016/j.neubiorev.2016.03.019

22. Ghanizadeh A (2010) Comorbidity of enuresis in children with attention-deficit/hyperactivity disorder. J Atten Disord 13(5):464-467

23. Kaiser M-L, Schoemaker MM, Albaret J-M, Geuze RH (2015) What is the evidence of impaired motor skills and motor control among children with attention deficit hyperactivity disorder (ADHD)? Systematic review of the literature. Res Dev Disabil 36C:338-357. https://doi.org/10.1016/j.ridd.2014.09.023
24. Tseng MH, Henderson A, Chow SMK, Yao G (2004) Relationship between motor proficiency, attention, impulse, and activity in children with ADHD. Dev Med Child Neurol 46(6):381-388

25. Rosa Neto F, Goulardins JB, Rigoli D, Piek JP, de Oliveira JA (2015) Motor development of children with attention deficit hyperactivity disorder. Revista Brasileira De Psiquiatria (Sao Paulo, Brazil: 1999) 37(3):228-234. https://doi. org/10.1590/1516-4446-2014-1533

26. Valera EM, Faraone SV, Murray KE, Seidman LJ (2007) Metaanalysis of structural imaging findings in attention-deficit/hyperactivity disorder. Biol Psychiat 61(12):1361-1369. https://doi. org/10.1016/j.biopsych.2006.06.011

27. Gillberg C, Gillberg IC, Rasmussen P, Kadesjö B, Söderström H, Råstam M et al (2004) Co-existing disorders in ADHD-implications for diagnosis and intervention. Eur Child Adolesc Psychiatry 13(Suppl 1):I80-I92. https://doi.org/10.1007/s00787-004-1008-4

28. Fliers E, Rommelse N, Vermeulen SHHM, Altink M, Buschgens CJM, Faraone SV et al (2008) Motor coordination problems in children and adolescents with ADHD rated by parents and teachers: effects of age and gender. J Neural Transm (Vienna, Austria: 1996) 115(2):211-220. https://doi.org/10.1007/s0070 2-007-0827-0

29. Fliers E, Vermeulen S, Rijsdijk F, Altink M, Buschgens C, Rommelse $\mathrm{N}$ et al (2009) ADHD and poor motor performance from a family genetic perspective. J Am Acad Child Adolesc Psychiatry 48(1):25-34. https://doi.org/10.1097/CHI.0b013e31818b1ca2

30. Fliers EA, de Hoog MLA, Franke B, Faraone SV, Rommelse NNJ, Buitelaar JK, Nijhuis-van der Sanden MWG (2010) Actual motor performance and self-perceived motor competence in children with attention-deficit hyperactivity disorder compared with healthy siblings and peers. J Dev Behav Pediatr JDBP 31(1):3540. https://doi.org/10.1097/DBP.0b013e3181c7227e

31. Magalhães LC, Missiuna C, Wong S (2006) Terminology used in research reports of developmental coordination disorder. Dev Med Child Neurol 48(11):937-941. https://doi.org/10.1017/S0012 162206002040

32. Arnsten AFT (2006) Fundamentals of attention-deficit/hyperactivity disorder: circuits and pathways. J Clin Psychiatry 67(Suppl 8):7-12

33. Fliers EA, Vasquez AA, Poelmans G, Rommelse N, Altink M, Buschgens $C$ et al (2012) Genome-wide association study of motor coordination problems in ADHD identifies genes for brain and muscle function. World J Biol Psychiatry Off J World Feder Soc Biol Psychiatry 13(3):211-222. https://doi.org/10.3109/15622 975.2011.560279

34. Fong SSM, Tsang WWN, Ng GYF (2012) Altered postural control strategies and sensory organization in children with developmental coordination disorder. Hum Mov Sci 31(5):1317-1327. https ://doi.org/10.1016/j.humov.2011.11.003

35. McLeod KR, Langevin LM, Goodyear BG, Dewey D (2014) Functional connectivity of neural motor networks is disrupted in children with developmental coordination disorder and attentiondeficit/hyperactivity disorder. NeuroImage Clin 4:566-575

36. Zwicker JG, Harris SR, Klassen AF (2013) Quality of life domains affected in children with developmental coordination disorder: a systematic review. Child Care Health Dev 39(4):562-580. https ://doi.org/10.1111/j.1365-2214.2012.01379.x

37. Langmaid RA, Papadopoulos N, Johnson BP, Phillips J, Rinehart NJ (2016) Movement scaling in children with ADHD-combined type. J Atten Disord 20(2):131-137. https://doi.org/10.1177/10870 54713493317

38. Gurevitz M, Geva R, Varon M, Leitner Y (2014) Early markers in infants and toddlers for development of ADHD. J Atten Disord 18(1):14-22. https://doi.org/10.1177/1087054712447858

39. Arnett AB, Macdonald B, Pennington BF (2013) Cognitive and behavioral indicators of ADHD symptoms prior to school 
age. J Child Psychol Psychiatry 54(12):1284-1294. https://doi. org/10.1111/jcpp.12104

40. Van Damme T, Simons J, Sabbe B, Van West D (2015) Motor abilities of children and adolescents with a psychiatric condition: a systematic literature review. World J Psychiatry 5(3):315

41. Jeyaseelan D, O'Callaghan M, Neulinger K, Shum D, Burns Y (2006) The association between early minor motor difficulties in extreme low birth weight infants and school age attentional difficulties. Early Hum Dev 82(4):249-255. https://doi. org/10.1016/j.earlhumdev.2005.10.012

42. Hadders-Algra M, Groothuis AM (1999) Quality of general movements in infancy is related to neurological dysfunction, ADHD, and aggressive behavior. Dev Med Child Neurol 41(6):381-391

43. Hadders-Algra M, Bouwstra H, Groen SE (2009) Quality of general movements and psychiatric morbidity at 9 to 12 years. Early Hum Dev 85(1):1-6. https://doi.org/10.1016/j.earlhumdev .2008.05.005

44. Butcher PR, van Braeckel K, Bouma A, Einspieler C, Stremmelaar EF, Bos AF (2009) The quality of preterm infants' spontaneous movements: an early indicator of intelligence and behavior at school age. J Child Psychol Psychiatry 50(8):920-930. https://doi.org/10.1111/j.1469-7610.2009.02066.x

45. Jacobvitz D, Sroufe LA (1987) The early caregiver-child relationship and attention-deficit disorder with hyperactivity in kindergarten: a prospective study. Child Dev 58(6):1496-1504

46. Jaspers M, de Winter AF, Buitelaar JK, Verhulst FC, Reijneveld SA, Hartman CA (2013) Early childhood assessments of community pediatric professionals predict autism spectrum and attention deficit hyperactivity problems. J Abnorm Child Psychol 41(1):7180. https://doi.org/10.1007/s10802-012-9653-4

47. Johnson P, Ahamat B, Mcconnachie A, Puckering C, Marwick H, Furnivall D et al (2014) Motor activity at age one year does not predict ADHD at seven years: infant motor activity and ADHD. Int J Methods Psychiatr Res 23(1):9-18. https://doi.org/10.1002/ mpr. 1436

48. Lemcke S, Parner ET, Bjerrum M, Thomsen PH, Lauritsen MB (2016) Early development in children that are later diagnosed with disorders of attention and activity: a longitudinal study in the Danish National Birth Cohort. Eur Child Adolesc Psychiatry 25(10):1055-1066. https://doi.org/10.1007/s00787-016-0825-6

49. Downs SH, Black N (1998) The feasibility of creating a checklist for the assessment of the methodological quality both of randomised and non-randomised studies of health care interventions. J Epidemiol Community Health 52(6):377-384

50. Buitelaar NJL, Posthumus JA, Buitelaar JK (2015) ADHD in childhood and/or adulthood as a risk factor for domestic violence or intimate partner violence: a systematic review. J Atten Disord. https://doi.org/10.1177/1087054715587099

51. Hadders-Algra M, Van Eykern LA, Klip-Van den Nieuwendijk AW, Prechtl HF (1992) Developmental course of general movements in early infancy. II. EMG correlates. Early Hum Dev 28(3):231-251

52. Hadders-Algra M, Klip-Van den Nieuwendijk A, Martijn A, van Eykern LA (1997) Assessment of general movements: towards a better understanding of a sensitive method to evaluate brain function in young infants. Dev Med Child Neurol 39(2):88-98

53. Prechtl HF (1990) Qualitative changes of spontaneous movements in fetus and preterm infant are a marker of neurological dysfunction. Early Hum Dev 23(3):151-158

54. Frankenburg WK, Dodds JB (1967) The Denver developmental screening test. J Pediatr 71(2):181-191

55. Achenbach TM (1991) Integrative guide for the $1991 \mathrm{CBCL} / 4-18$, YSR, and TRF profiles. Department of Psychiatry, University of Vermont, Vermont

56. Carey WB (1970) A simplified method for measuring infant temperament. J Pediatr 77(2):188-194

57. Brazelton TB (1973) Assessment of the infant at risk. Clin Obstet Gynecol 16(1):361-375

58. Wiechen JV (1988) Ontwikkelingsonderzoek op het consultatiebureau. Werkboek bij het herzien van het Van Wiechenschema. Landelijke Vereniging Thuiszorg, Utrecht

59. Thorpe M (2003) Infant formula supplemented with DHA: are there benefits? J Am Diet Assoc 103(5):551-552

60. Sprich-Buckminster S, Biederman J, Milberger S, Faraone SV, Lehman BK (1993) Are perinatal complications relevant to the manifestation of ADD? Issues of comorbidity and familiality. $\mathrm{J}$ Am Acad Child Adolesc Psychiatry 32(5):1032-1037. https://doi. org/10.1097/00004583-199309000-00023

61. Batstra L, Neeleman J, Elsinga C, Hadders-Algra M (2006) Psychiatric morbidity is related to a chain of prenatal and perinatal adversities. Early Hum Dev 82(11):721-729. https://doi. org/10.1016/j.earlhumdev.2006.03.003

62. Hadders-Algra M (2004) General movements: a window for early identification of children at high risk for developmental disorders. J Pediatr 145(2):S12-S18

63. Lüchinger AB, Hadders-Algra M, van Kan CM, de Vries JIP (2008) Fetal onset of general movements. Pediatr Res 63(2):191195. https://doi.org/10.1203/PDR.0b013e31815ed03e

64. Auerbach JG, Atzaba-Poria N, Berger A, Landau R (2004) Emerging developmental pathways to ADHD: possible path markers in early infancy. Neural Plast 11(1-2):29-43 